\title{
Editorial
}

\section{Upper and Lower Limb Orthopaedics: Prevention of CRPS \& Other Traumatology}

A flying invitation was send to me for a guest editorship to this journal. This is probably the result of earlier publications of our Dutch study group: two randomized clinical trials (RCT's) on distal radial fractures and vitamin C in the prevention of complex regional pain syndrome type I (CRPS). CRPS is an affliction that can occur after a trauma to an arm or leg. The prevalence in adults is highest in the upper limb. For children this is the lower extremity. As the pathogenesis of CRPS is still not clear yet, and there is no definitive treatment for this syndrome, the emphasis should lie in prevention of CRPS. The morbidity and costs in health care justify the search for a means to prevent CRPS in traumatology and after elective (orthopaedic) surgery.

Ascorbic acid is a water-soluble vitamin that protects against scurvy and it acts as a strong anti-oxidant. By scavenging radicals, vitamin $\mathrm{C}$ halts free-radical reactions and prevents the propagation of chain reactions. From a meta-analysis of the mentioned RCT's it was concluded that vitamin C reduces the chance of the occurrence of CRPS after wrist fractures. Other indications and applications are under survey and two studies are being described and discussed in this issue, which contains furthermore a miscellaneous contribution from orthopaedic and trauma surgeons from the Netherlands.

Other articles we contribute on the upper limb are prosthetic replacements in hand, wrist and shoulder, and fracture and dislocation treatment.

Lower limb issues are compartment syndrome and cartilage repair in the knee.

The trauma mechanisms and injuries after go-karting are diverse and could also lead to vertebral and pelvic fractures.

So we hope that the reader finds divertissement in this issue from Dutch soil, named after The Flying Dutchman: hot topic issue from the Netherlands on upper \& lower limb orthopaedics, prevention of CRPS \& other traumatology.

Paul E. Zollinger

(Guest Editor)

Orthopaedic Surgeon

Department of Orthopaedics \& Traumatology

Ziekenhuis Rivierenland

Pres. Kennedylaan 1

4002 WP Tiel

The Netherlands

E-mail: PE.ZZollinger@tiscali.nl

(C) Paul E. Zollinger; Licensee Bentham Open.

This is an open access article licensed under the terms of the Creative Commons Attribution Non-Commercial License (http://creativecommons.org/licenses/bync/ 3.0/) which permits unrestricted, non-commercial use, distribution and reproduction in any medium, provided the work is properly cited. 